\title{
HPTLC Fingerprinting and Cholinesterase Inhibitory and Metal-Chelating Capacity of Various Citrus Cultivars and Olea europaea
}

\author{
Fatma Sezer Senol ${ }^{1}$, Anita Ankli ${ }^{2}$, Eike Reich ${ }^{2}$ and Ilkay Erdogan Orhan ${ }^{1 *}$ \\ ${ }^{1}$ Department of Pharmacognosy, Faculty of Pharmacy, Gazi University, TR-06330 Ankara, Turkey \\ ${ }^{2}$ CAMAG Laboratory, Sonnenmattstrasse 11, CH-4132 Muttenz, Switzerland
}

Received: April 22, 2015

Accepted: April 14, 2016

\begin{abstract}
Summary
Inhibitory activity of thirty-one ethanol extracts obtained from albedo, flavedo, seed and leaf parts of 17 cultivars of Citrus species from Turkey, the bark and leaves of Olea europaea L. from two locations (Turkey and Cyprus) as well as caffeic acid and hesperidin was tested against acetylcholinesterase (AChE) and butyrylcholinesterase (BChE), related to the pathogenesis of Alzheimer's disease, using ELISA microtiter assays at $500 \mu \mathrm{g} / \mathrm{mL}$. Metal-chelating capacity of the extracts was also determined. BChE inhibitory effect of the Citrus sp. extracts was from $(7.7 \pm 0.7)$ to $(70.3 \pm 1.1) \%$, whereas they did not show any inhibition against AChE. Cholinesterase inhibitory activity of the leaf and bark ethanol extracts of O. europaea was very weak $((10.2 \pm 3.1)$ to $(15.0 \pm 2.3) \%)$. The extracts had either no or low metal-chelating capacity at $500 \mu \mathrm{g} / \mathrm{mL}$. HPTLC fingerprinting of the extracts, which indicated a similar phytochemical pattern, was also done using the standards of caffeic acid and hesperidin with weak cholinesterase inhibition. Among the screened extracts, the albedo extract of $C$. limon 'Interdonato', the flavedo extracts of 'Kara Limon' and 'Cyprus' cultivars and the seed extract of $C$. maxima appear to be promising as natural BChE inhibitors.
\end{abstract}

Key words: Citrus sp., Olea europaea, cholinesterase inhibition, metal-chelating activity, HPTLC

\section{Introduction}

Alzheimer's disease (AD) is a neurological disorder and the most common cause of dementia. It is a slowly progressive and degenerative disease that leads to loss of memory, decline in thinking and language skills. The pathogenesis of AD has been so far explained by cholinergic and amyloid hypotheses, and it has been stated that only drugs acting on cholinergic system have moderate, but steady effects in clinical trials (1). The cholinergic hypothesis is based on insufficiency of the acetylcholine (ACh) level in the brains of AD patients, which is hydrolyzed by acetylcholinesterase (AChE, EC 3.1.1.7) (2). On the other hand, the evidence has shown that butyrylcholinesterase (BChE, EC 3.1.1.8), also known as pseudocholinesterase, takes a slight part in hydrolyzing brain
ACh levels in addition to its possible action in the etiology and progression of the disease (3). Thus, inhibition of both $\mathrm{AChE}$ and $\mathrm{BChE}$ is an important target for the development of new anti-Alzheimer drugs. Since AD is multi-faceted disease, it is also strongly associated with metal ion dyshomeostasis and oxidative stress (4). Dysregulation of some transition metals such as iron, aluminum or copper has been very important in formation of oxidative stress and cellular damage relevant to some neurodegenerative diseases including AD and Parkinson's disease $(5,6)$. Therefore, it is strategically advantageous to have a drug candidate with both cholinesterase inhibition and metal-chelating properties for the treatment of $\mathrm{AD}$ as the need for development of novel drugs remains. 
Citrus species (Rutaceae) bearing widely consumed fruits of nutritional and industrial importance are rich in flavonoid derivatives, i.e. hesperidin, naringin and polymethoxylated flavonoids, whose distributions differ in Citrus tissues including albedo, flavedo, pericarp (peel) and seed (7). Earlier studies have revealed that the phenolic compounds exist in higher amounts in Citrus peel than in other parts of Citrus fruit, such as seeds, leaves or flowers (8). Olea europaea L. (olive) from Oleaceae family is an evergreen tree particularly native to the Mediterranean region. In addition to being edible, olive tree is also considered as a medicinal plant. Due to nutritional and health aspects of Citrus sp. and O. europaea, their edible tissues have been extensively investigated for their various biological activities and phytochemical content. Nevertheless, there have been relatively few reports on health-promoting values of non-edible tissues of Citrus fruits and $O$. europaea. Hence, in the present study, attempts have been made to investigate inhibitory effect of 31 ethanol extracts from 17 Citrus cultivars from Turkey as well as the bark and leaves of olive trees growing in Turkey and Cyprus against AChE and BChE using ELISA microtiter assays. Additionally, high-performance thin layer chromatography (HPTLC) fingerprinting of the extracts was done using hesperidin and caffeic acid standards, two phenolic substances commonly found in Citrus species.

\section{Materials and Methods}

\section{Plant materials and extraction}

The samples of 17 Citrus cultivars were obtained from The West Mediterranean Agricultural Research Institute (BATEM, Antalya Province, Turkey) in 2011, where they are cultivated in the experimental fields. The bark and leaf samples of Olea europaea were collected from Denizli Province (western Turkey) and the leaf samples from Mehmetcik village at Famagusta town (northern Cyprus) in 2012. The pericarps (peels) of the Citrus fruits were peeled and carefully separated into their albedo (whitish) and flavedo (yellow or orange) parts. All plant samples were dried at room temperature in shadow and coarsely ground prior to the extraction. The dried and powdered samples were extracted at room temperature by percolation with ethanol (80\%; Carlo Erba, Val de Reuil, France). All of the extracts were concentrated using a rotary evaporator (BÜCHI Labortechnik AG, Flawil, Switzerland) in vacuo until a solid extract of each sample was obtained.

\section{Microtitre assays for anticholinesterase activity}

AChE and BChE inhibitory potential of the extracts was determined by modified spectrophotometric method of Ellman et al. (9) as described in our previous publication (10). Electric eel acetylcholinesterase (TypeVI-S, EC 3.1.1.7) and horse serum butyrylcholinesterase (EC 3.1.1.8) were used as the enzyme sources purchased from Sigma-Aldrich (St. Louis, MO, USA). Acetylthiocholine iodide and butyrylthiocholine chloride (Sigma-Aldrich) were employed as the substrates for the reaction, while 5,5'-dithio-bis(2-nitrobenzoic) acid (DTNB; Sigma-Aldrich) was the colouring agent. A volume of $140 \mu \mathrm{L}$ of $0.1 \mathrm{mM}$ sodium phosphate buffer ( $\mathrm{pH}=8.0$ ), $20 \mu \mathrm{L}$ of $0.2 \mathrm{M}$ DTNB, 20 $\mu \mathrm{L}$ of the sample solutions and $20 \mu \mathrm{L}$ of $0.2 \mathrm{M} \mathrm{AChE/}$ BChE solution were added with multichannel automatic pipette (Gilson S.A.S., Villiers le Bel, France) to a 96-well microplate and incubated for $15 \mathrm{~min}$ at $25^{\circ} \mathrm{C}$. The reaction was then initiated with the addition of $10 \mu \mathrm{L}$ of $0.2 \mathrm{M}$ acetylthiocholine iodide/butyrylthiocholine chloride. Formation of the yellow 5-thio-2-nitrobenzoate anion resulted from the reaction of DTNB with thiocholines after hydrolysis of acetylthiocholine iodide/butyrylthiocholine chloride, which was monitored at $412 \mathrm{~nm}$ utilizing a 96-well microplate reader VersaMax ${ }^{\mathrm{TM}}$ (Molecular Devices, Sunnyvale, CA, USA). Galanthamine, purchased from Sigma-Aldrich, was employed as the reference.

\section{Data processing for enzyme inhibition assays}

The measurements and calculations were evaluated by using Softmax ${ }^{\circledR}$ PRO v. 4.3.2.LS software (Molecular Devices). Percentage inhibition (I) of AChE/BChE was determined by comparison of reaction rates of test samples with the blank sample (ethanol in phosphate buffer, $\mathrm{pH}=8)$, and calculated using the equation given below:

$$
\mathrm{I}=\left(\left(A_{\text {blank }}-A_{\text {sample }}\right) / A_{\text {blank }}\right) \cdot 100
$$

where $A_{\text {blank }}$ is the absorbance of the control reaction (containing all reagents except the test sample), and $A_{\text {sample }}$ is the absorbance of the extracts. Data was expressed as average inhibition \pm standard error of the mean (SEM), which were obtained from three independent experiments.

\section{Determination of metal-chelating capacity by $\mathrm{Fe}^{2+}$-ferrozine test system}

The metal-chelating capacity of the extracts was estimated with the method of Chua et al. (11) using $\mathrm{Fe}^{2+}$-ferrozine test system followed by ELISA method. In brief, the samples $(200 \mu \mathrm{L}$ each) dissolved in ethanol (75\%) were incubated with $2 \mathrm{mM} \mathrm{FeCl}_{2}$ solution (Sigma Chemical Co., Steinheim, Germany). The reaction was started after the addition of $40 \mu \mathrm{L}$ of $5 \mathrm{mM}$ ferrozine (Sigma Chemical Co.) solution, which was shaken gently and left to rest for 10 min at ambient temperature. The absorbance of the reaction mixture as well as ethylenediaminetetraacetic acid (EDTA; Sigma Chemical Co.) as the reference was measured at $562 \mathrm{~nm}$ using a Unico $4802 \mathrm{UV} / \mathrm{Vis}$ spectrophotometer (Dayton, NJ, USA). Metal chelation capacity was measured as a percentage inhibition of $\mathrm{Fe}^{2+}$-ferrozine complex calculated using Eq. 1. The experiments were run in triplicate and the results were expressed as average values with SEM.

\section{HPTLC analysis}

HPTLC analysis was performed on a CAMAG (Muttenz, Switzerland) apparatus equipped with automatic TLC sampler 4, twin trough chamber $(20 \mathrm{~cm} \times 10 \mathrm{~cm})$, chromatogram immersion device III, TLC plate heater III, automatic development chamber ADC2 and visualizer. The extracts and standards, i.e. caffeic acid (Carl Roth $\mathrm{GmbH}$, Zurich, Switzerland) and hesperidin (Acros Organics, Basel, Switzerland) at the concentrations of 5 and $0.2 \mathrm{mg} / \mathrm{mL}$, respectively, were dissolved in methanol of ultra gradient HPLC grade (Carl Roth $\mathrm{GmbH}$ ). The volume of each sample was 10 or $15 \mu \mathrm{L}$. Development conditions were as fol- 
lows: relative humidity $\mathrm{RH}=33 \%$, solution saturation 20 $\mathrm{min}$, developing distance from application position/lower edge of the plate of $62 / 70 \mathrm{~mm}$, developing solvent ethyl acetate (Acros Organics, Basel, Switzerland)/formic acid (Acros Organics)/water (CAMAG) in a ratio of 75:15:10, developing time $20 \mathrm{~min}$, and plate drying time $5 \mathrm{~min}$. The plates used were HPTLC glass Si 60 F254 $(20 \mathrm{~cm} \times 10 \mathrm{~cm}$, model HX308464; Merck Co., Darmstadt, Germany), while visualization of the spots was achieved with $\mathrm{AlCl}_{3}$ and natural product polyethylene glycol (PEG) 400 (Merck Co.).

\section{Results and Discussion}

\section{Cholinesterase inhibitory and metal chelation activities of extracts}

The results of enzyme inhibition tests show that Citrus extracts at the concentration of $500 \mu \mathrm{g} / \mathrm{mL}$ did not affect AChE activity, while Olea europaea leaf extracts slightly inhibited (below $16 \%$ ) both enzymes (Table 1). On the other hand, quite variable inhibition rates of Citrus extracts (between $(7.72 \pm 0.71)$ and $(70.28 \pm 1.12) \%)$ were observed against $\mathrm{BChE}$. Caffeic acid and hesperidin, tested in the same manner but at the concentration of $100 \mu \mathrm{g} / \mathrm{mL}$, had (6.0 \pm 2.5$)$ and $(27.3 \pm 1.2) \%$ of AChE inhibition as well as $(24.1 \pm 0.9)$ and $(17.7 \pm 4.2) \%$ of BChE inhibition, respectively. The extracts had either no or very low (below $13 \%$ ) metal-chelating capacity (Table 1), while caffeic acid and hesperidin were not tested in this assay.

\section{HPTLC profile of the extracts}

According to the HPTLC profiles of the extracts screened in the current study, the flavedo extracts had more intense zones at $366 \mathrm{~nm}$ than the albedo extracts. Looking at the results of white light reflectance transmittance, it can be observed that the yellow zones of the albedo samples are more intense than the corresponding yellow zones of the flavedo samples. Our findings indicate that it is possible to discriminate Citrus aurantium, $C$. deliciosa, C. limon, C. maxima/C. paradisi and C. sinensis/C. reticulata. The fingerprints of $C$. maxima and $C$. paradisi look very similar, thus, these two species cannot be discriminated. This is also the case for C. sinensis and C. reticulata. As seen in Fig. 1, the fingerprints of the albedo and flavedo extracts of $C$. aurantium look very similar to each other under white light, with a strong red zone at retention factor $\left(R_{\mathrm{F}}\right)$ of approx. 0.36 and several yellow zones above it. All extracts belonging to $C$. limon species had a similar fingerprint with a characteristic red zone at $R_{\mathrm{F}}$ of approx. 0.39 under white light. The fingerprints of the flavedo and albedo samples of C. maxima each had a yellow zone with a higher $R_{\mathrm{F}}$ value than hesperidin. A parallel fingerprint was observed for all extracts of $C$. paradisi cultivars that contained hesperidin, while the extracts obtained from C. reticulata and C. sinensis 'Navelina' resemble each other (Fig. 2). Among the analyzed extracts in Fig. 3, all the C. sinensis cultivars had two yellow zones, one of them with the same $R_{\mathrm{F}}$ value as hesperidin. The leaf extracts of O. europaea collected from the two locations exhibited quite analogous phytochemical profiles, whereas the bark extract of this plant had a different fingerprint than those of the leaf extracts.
A number of studies have demonstrated a potent cholinesterase inhibitory effect of various Citrus species, particularly against AChE, such as C. unshiu (12), C. paradisi (13), C. junos (14), C. medica 'Diamante' (15), C. hystrix (16), C. depressa (17), C. aurantifolia, C. aurantium and C. bergamia (18-20), C. maxima, C. paradisi, C. limon, C. sinensis and C. reticulata (21-23). The health effects of Citrus fruits have been principally attributed to the existence of phenolic compounds including flavonoids and phenolic acids. Some of the studies led to the isolation of flavonoids as the active components such as naringenin, the flavanone isolated from the peel extract of $C$. junos, which inhibited $\mathrm{AChE}$ at low level $\left(\mathrm{IC}_{50}=(621 \pm 7.8) \mu \mathrm{g} / \mathrm{mL}\right)$ as compared to that of the reference physostigmine $\left(\mathrm{IC}_{50}=(0.07 \pm\right.$ $0.0) \mu \mathrm{g} / \mathrm{mL}$ ) (15). Naringenin also exerted antiamnesic effect in vivo. Similarly, nobiletin, 8-demethoxynobiletin and 6-demethoxynobiletin (60-76 \% of control at $100 \mu \mathrm{M}$ of each compound) isolated from the peel extract of $C$. depressa were concluded to be the active components for the marked anti-AChE effect of this plant (17).

However, in another study (16), furanocoumarins identified as $(R)-(+)-6^{\prime}$-hydroxy-7'-methoxybergamottin, $(R)-(+)-6^{\prime}, 7^{\prime}$-dihydroxybergamottin and (+)-isoimperatorin $\left(\mathrm{IC}_{50}=(11.2 \pm 0.1),(15.4 \pm 0.3)\right.$ and $(23.0 \pm 0.2) \mu \mathrm{M}$, respectively) were suggested to be the compounds responsible for the peel hexane and dichloromethane extracts of the C. hystrix fruits. Other coumarin derivatives, nootkatone and auraptene isolated from the essential oil of C. paradisi, were revealed to inhibit only $17-24 \%$ of AChE activity, at the concentration of $1.62 \mu \mathrm{g} / \mathrm{mL}$ (13). Fruit juices of several Citrus cultivars, i.e. C. maxima (shaddock), C. paradisi (grapefruit), C. limon (lemon), C. sinensis (orange) and C. reticulata (tangerine) and the aqueous extracts from C. sinensis, C. paradisi and C. maxima as well as the essential oil isolated from the peels of $C$. aurantifolia, $C$. aurantium and C. bergamia were reported to exert selective AChE inhibitory activity varying from moderate to remarkable levels $(18,21,22)$, which seems contrary to our findings on selective BChE inhibition of the Citrus cultivars screened herein (Table 1). Nevertheless, C. limon was reported to have a weak cholinesterase inhibitory activity, dissimilar to most of our data on C. limon cultivars (23).

On the other hand, the leaves of Citrus cultivars have been examined in a very few studies, one of which was performed with the leaf essential oil of $C$. aurantifolia. The leaf oil was revealed to have $\mathrm{IC}_{50}$ values of $(139 \pm 35)$ and $(42 \pm 5) \mu \mathrm{g} / \mathrm{mL}$ on AChE and BChE, respectively (19), while Loizzo et al. (20) investigated the leaf hexane extract of $C$. aurantifolia with a marked AChE inhibitory effect. In the present study, the leaf ethanol extract of $C$. aurantium inhibited $(46.37 \pm 0.54) \%$ of BChE.

The computational studies described stronger AChE inhibitory effect of naringin than hesperidin (24), which inhibited $(27.33 \pm 1.16) \%$ of AChE in the current study. Without any doubt, hesperidin, present in most of the Citrus extracts screened in the HPTLC analysis, could be one of the compounds contributing somewhat to BChE inhibitory effects of the extracts. Caffeic acid, a dominant phenolic compound available in many Citrus cultivars $(25,26)$, was reported earlier to exhibit either low inhibitory activity $((11.05 \pm 1.03) \%$ at $100 \mu \mathrm{g} / \mathrm{mL})$ against $\mathrm{AChE}(27)$ and 
Table 1. Cholinesterase inhibitory and metal-chelating activities of ethanol extracts of Citrus sp. and Olea europaea at mass concentration of $500 \mu \mathrm{g} / \mathrm{mL}$ (unless otherwise stated)

\begin{tabular}{|c|c|c|c|c|c|}
\hline \multirow[t]{2}{*}{ Species } & \multirow[t]{2}{*}{ Plant part } & \multirow{2}{*}{$\frac{Y}{\%}$} & $\begin{array}{l}\text { Inhibition against } \\
\text { AChE }^{\mathrm{a}}\end{array}$ & $\begin{array}{c}\text { Inhibition against } \\
\text { BChE }^{\mathrm{a}}\end{array}$ & $\begin{array}{c}\text { Metal-chelating } \\
\text { capacity }\end{array}$ \\
\hline & & & $\%$ & $\%$ & $\%$ \\
\hline \multirow{3}{*}{ Citrus aurantium } & albedo & 5.87 & - & $7.7 \pm 0.7^{* * * *}$ & - \\
\hline & flavedo & 8.48 & - & $54.0 \pm 0.8^{* * * *}$ & - \\
\hline & leaf & 22.02 & $-{ }^{b}$ & $46.4 \pm 0.5^{* * * *}$ & $10.9 \pm 0.2^{* * * *}$ \\
\hline Citrus deliciosa & pericarp & 10.81 & - & $34.2 \pm 0.8^{* * * *}$ & - \\
\hline \multirow{2}{*}{ Citrus limon 'Interdonato' } & albedo & 11.74 & - & $51.6 \pm 1.9^{* * * * *}$ & - \\
\hline & flavedo & 13.83 & - & - & - \\
\hline \multirow{2}{*}{ Citrus limon 'Kara Limon' } & albedo & 14.17 & - & $19.6 \pm 0.3^{* * * *}$ & - \\
\hline & flavedo & 20.86 & - & $47.0 \pm 1.4^{* * * *}$ & - \\
\hline \multirow{2}{*}{ Citrus limon 'Cyprus' } & albedo & 7.23 & - & $27.8 \pm 5.8^{* * * * *}$ & - \\
\hline & flavedo & 14.56 & - & $70.3 \pm 1.1^{* *}$ & - \\
\hline \multirow{3}{*}{ Citrus maxima } & albedo & 14.48 & - & $23.7 \pm 2.6^{* * * *}$ & - \\
\hline & flavedo & 15.89 & - & $39.5 \pm 3.0^{* * * *}$ & - \\
\hline & seed & 11.42 & - & $69.9 \pm 1.9^{* * *}$ & - \\
\hline \multirow{2}{*}{ Citrus paradisi 'Henderson' } & albedo & 12.25 & - & $28.6 \pm 2.4^{* * * * *}$ & - \\
\hline & flavedo & 26.82 & - & $46.1 \pm 2.6^{* * * *}$ & - \\
\hline \multirow{2}{*}{ Citrus paradisi 'Red Blush’ } & albedo & 12.47 & - & $24.5 \pm 3.1^{* * * * *}$ & - \\
\hline & flavedo & 24.61 & - & $42.7 \pm 1.4^{* * * *}$ & - \\
\hline \multirow{2}{*}{ Citrus paradisi 'Star Ruby' } & albedo & 15.86 & - & $28.7 \pm 0.1^{* * * * *}$ & - \\
\hline & flavedo & 33.79 & - & $39.9 \pm 2.4^{* * * * *}$ & - \\
\hline Citrus reticulata 'Lee' & pericarp & 7.86 & - & $42.5 \pm 0.1^{* * * *}$ & - \\
\hline Citrus reticulata 'Nova' & pericarp & 9.37 & - & $40.4 \pm 1.4^{* * * * *}$ & - \\
\hline Citrus reticulata 'Blanco' $\times$ Citrus paradisi & pericarp & 11.39 & - & $19.5 \pm 0.4^{* * * *}$ & - \\
\hline \multirow{2}{*}{ Citrus sinensis 'Navelina' } & albedo & 9.49 & - & $12.3 \pm 3.3^{* * * * *}$ & - \\
\hline & flavedo & 18.00 & - & $19.5 \pm 0.3^{* * * *}$ & - \\
\hline \multirow{2}{*}{ Citrus sinensis 'Shamouti' } & albedo & 13.49 & - & $12.7 \pm 0.5^{* * * *}$ & - \\
\hline & flavedo & 16.45 & - & $7.5 \pm 0.6^{* * * * *}$ & $12.6 \pm 0.3^{* * * * *}$ \\
\hline \multirow{2}{*}{ Citrus sinensis 'Valencia Late' } & albedo & 7.56 & - & $25.2 \pm 2.8^{* * * * *}$ & - \\
\hline & flavedo & 15.36 & - & $25.6 \pm 0.4^{* * * * *}$ & - \\
\hline \multirow{2}{*}{ Citrus sinensis 'Washington Navel' } & albedo & 13.27 & - & $22.6 \pm 1.4^{* * * *}$ & - \\
\hline & flavedo & 22.80 & - & $25.6 \pm 0.1^{* * * *}$ & - \\
\hline Citrus japonica & pericarp & 13.42 & - & $14.3 \pm 0.0^{* * * *}$ & - \\
\hline Olea europaea (Turkey) & bark & 12.53 & $5.7 \pm 1.5^{* * * *}$ & $15.0 \pm 2.3^{* * * *}$ & $7.0 \pm 0.0^{* * * *}$ \\
\hline Olea europaea (Turkey) & leaf & 26.77 & $12.0 \pm 1.4^{* * * *}$ & $10.2 \pm 3.1^{* * * * *}$ & $4.8 \pm 2.7^{* * * * *}$ \\
\hline Olea europaea (Cyprus) & leaf & 32.61 & $11.1 \pm 1.6^{* * * * *}$ & $11.9 \pm 2.0^{* * * * *}$ & - \\
\hline Caffeic acid ${ }^{c}$ & & & $6.0 \pm 2.5^{* * * *}$ & $24.1 \pm 0.9^{* * * *}$ & $-{ }^{\mathrm{d}}$ \\
\hline Hesperidin $^{c}$ & & & $27.3 \pm 1.2^{* * * *}$ & $17.7 \pm 4.2^{* * * *}$ & - \\
\hline Galanthamine $^{e}$ & & & $94.5 \pm 3.8$ & $92.3 \pm 0.8$ & \\
\hline EDTA $^{\mathrm{f}}$ & & & & & $96.5 \pm 0.9$ \\
\hline
\end{tabular}

${ }^{a}$ Results are expressed as mean value \pm standard error of the mean $(N=3),{ }^{b}$ no inhibition/activity, ${ }^{\mathrm{c}}$ tested at $100 \mu \mathrm{g} / \mathrm{mL},{ }^{\mathrm{d}}$ not tested, ${ }^{e}$ reference for AChE and BChE inhibition assays at $100 \mu \mathrm{g} / \mathrm{mL}$, ${ }^{f}$ reference for metal-chelating capacity assay at $100 \mu \mathrm{g} / \mathrm{mL}$. ${ }^{*} \mathrm{p}<0.05$, ${ }^{* * *} \mathrm{p}<0.01,{ }^{* * * *} \mathrm{p}<0.001,{ }^{* * * * *} \mathrm{p}<0.0001$

$\mathrm{IC}_{50} \geq 200 \mu \mathrm{M}$ (28) or no inhibition (29), which is consistent with our result $((6.01 \pm 2.50) \%$ at $100 \mu \mathrm{g} / \mathrm{mL})$.

According to our literature survey, AChE inhibitory effects of the leaf extracts of the stored and fresh samples of O. europaea were $(69.2 \pm 6.0)$ and $(85.4 \pm 3.4) \%$ at $1 \mu \mathrm{g} / \mathrm{mL}$, respectively (30). Nevertheless, the leaf and bark extracts from O. europaea used in this study had insignificant effect on both AChE and BChE as compared to that of the reference (galanthamine).

Although a few studies demonstrated metal-chelating capacity of Citrus cultivars at various levels $(31,32)$, the Citrus extracts studied herein exerted either very low 

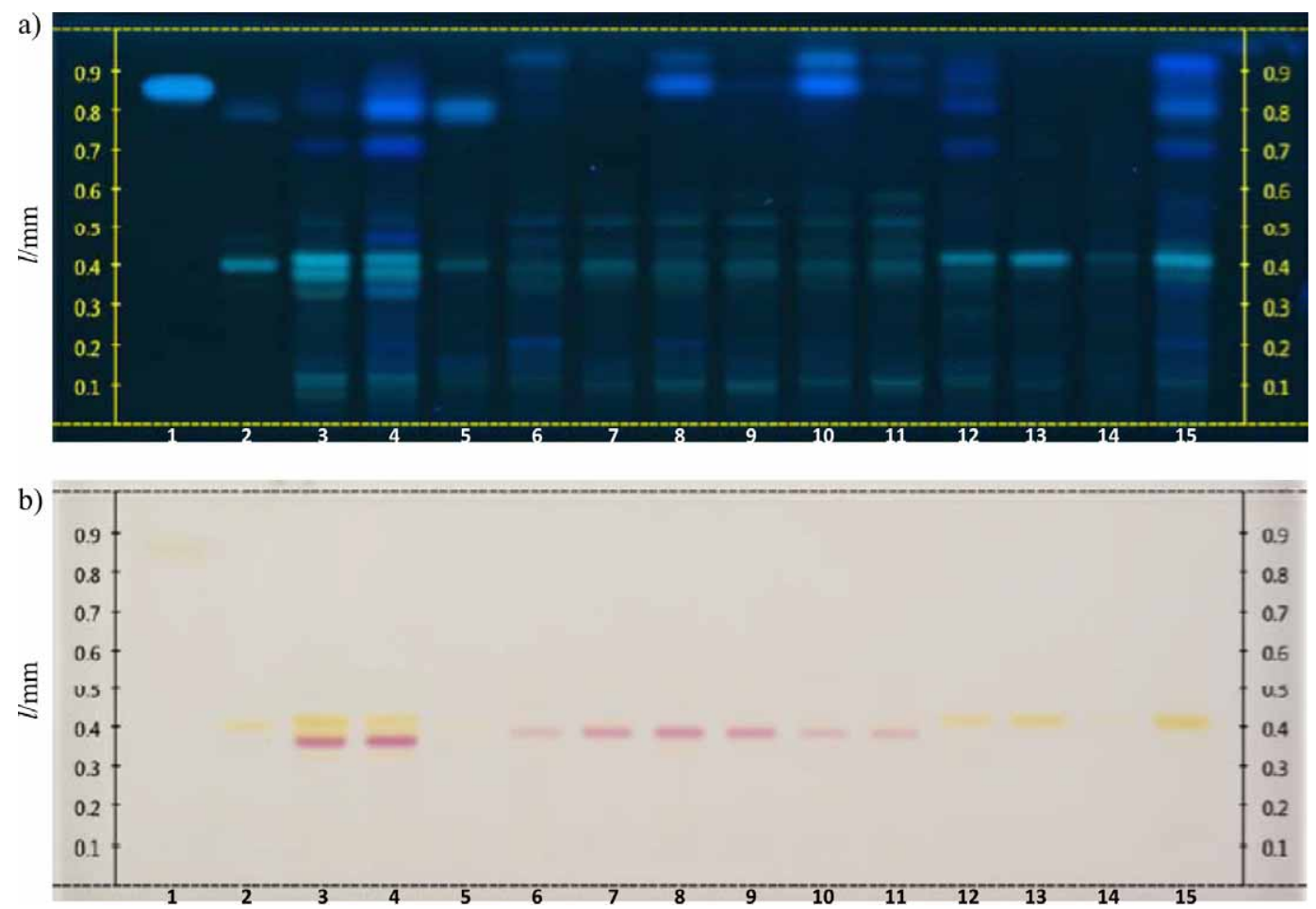

Fig. 1. HPTLC profiles of the Citrus extracts: a) image of the derivatized plate with $\mathrm{AlCl}_{3}$ under UV light at $366 \mathrm{~nm}$, and b) image of the derivatized plate under white light $\left(\mathrm{AlCl}_{3}\right.$, then natural product PEG 400). Lane $1=$ caffeic acid, lane 2=hesperidin, lanes 3 and $4=$ C. aurantium (albedo and flavedo), lane $5=C$. deliciosa (pericarp), lanes 6 and $7=C$. limon 'Interdonato' (flavedo and albedo), lanes 8 and 9=C. limon 'Kara Limon' (flavedo and albedo), lanes 10 and 11=C. limon 'Cyprus' (flavedo and albedo), lanes 12 and 13=C. maxima (flavedo and albedo), lanes 14 and 15=C. maxima. Volume of each sample was $10 \mu \mathrm{L}$, except in lane $15(15 \mu \mathrm{L})$
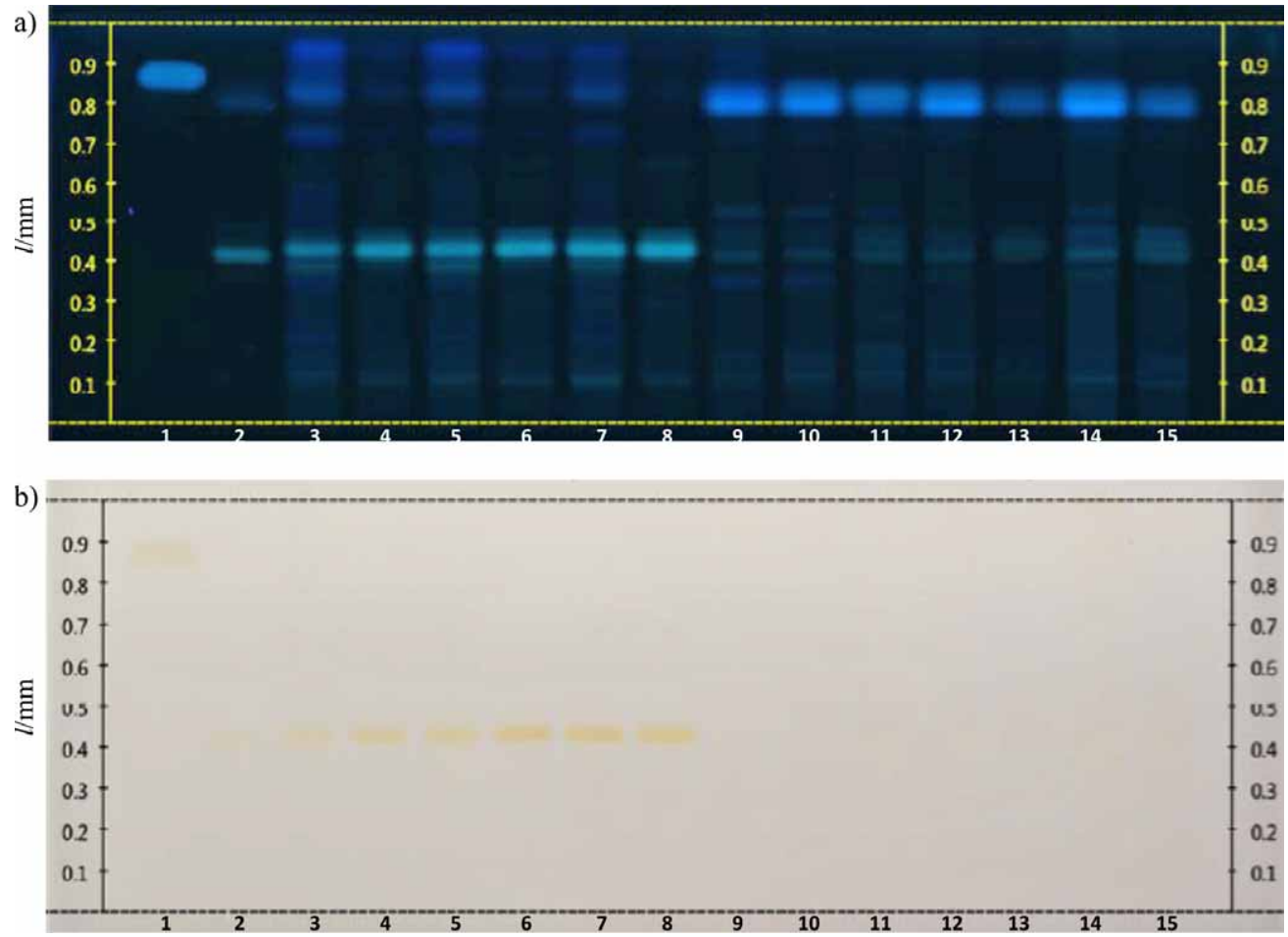

Fig. 2. HPTLC profiles of the Citrus extracts: a) image of the derivatized plate with $\mathrm{AlCl}_{3}$ under UV light at $366 \mathrm{~nm}$, and b) image of the derivatized plate under white light $\left(\mathrm{AlCl}_{3}\right.$, then natural product PEG 400). Lane 1=caffeic acid, lane 2=hesperidin, lanes 3 and $4=C$. paradisi 'Handerson' (flavedo and albedo), lanes 5 and $6=C$. paradisi 'Red Blush' (flavedo and albedo), lanes 7 and $8=C$. paradisi 'Star Ruby' (flavedo and albedo), lane 9=C. reticulata 'Lee' (pericarp), lane 10=C. reticulata 'Nova' (pericarp), lane 11=C. reticulata 'Blanco' $\times$ C. paradisi (pericarp), lanes 12 and $13=C$. sinensis 'Navelina' (flavedo and albedo), lanes 14 and $15=C$. sinensis 'Navelina' (flavedo and albedo). Volume of each sample was $10 \mu \mathrm{L}$, except in lanes 14 and $15(15 \mu \mathrm{L})$ 

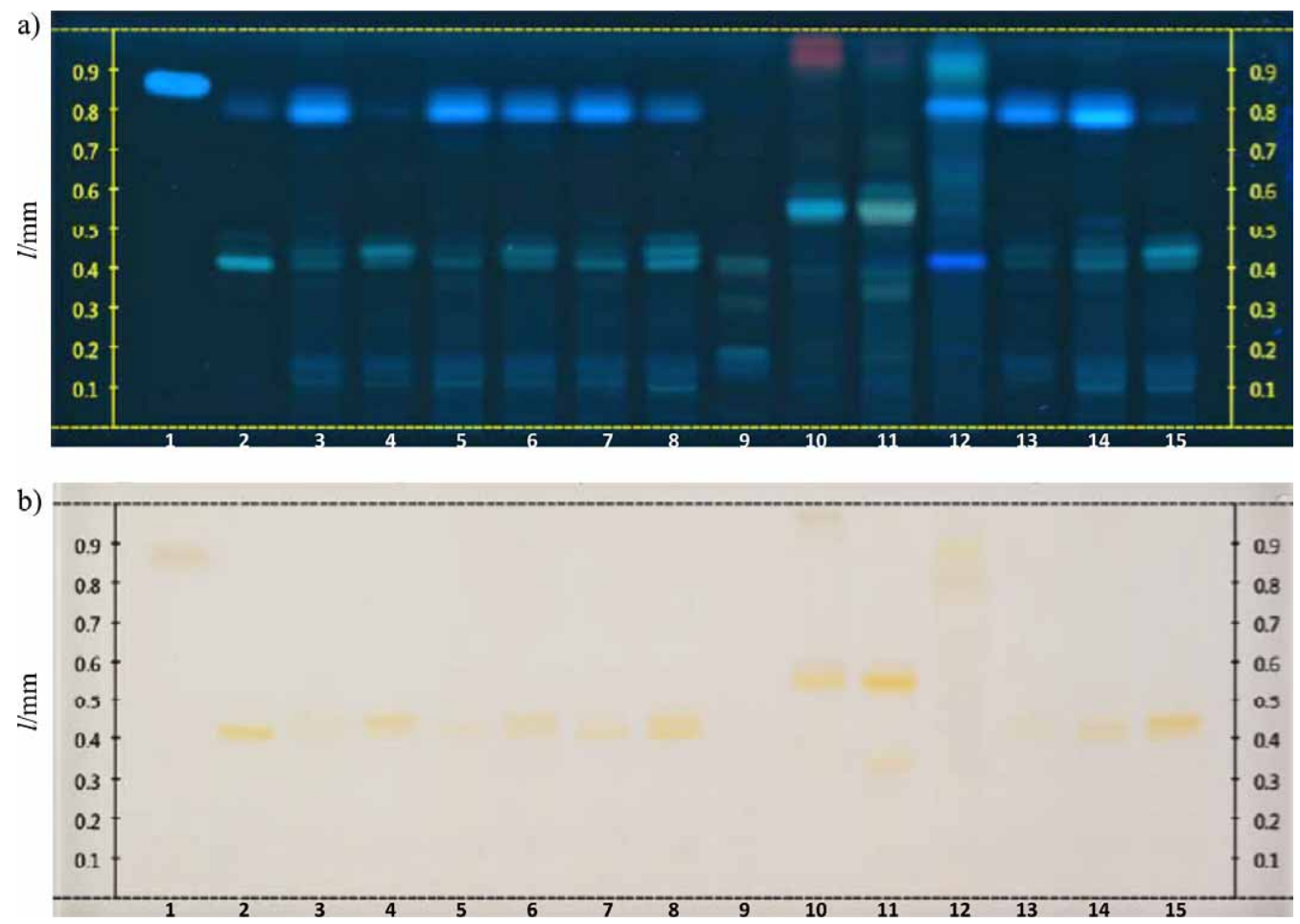

Fig. 3. HPTLC profiles of the Citrus and Olea europaea extracts: a) image of the derivatized plate with $\mathrm{AlCl}_{3}$ under UV light at $366 \mathrm{~nm}$, and $b$ ) image of the derivatized plate under white light $\left(\mathrm{AlCl}_{3}\right.$, then natural product PEG 400). Lane 1=caffeic acid, lane $2=$ hesperidin, lanes 3 and $4=C$. sinensis 'Shamouti' (flavedo and albedo), lanes 5 and $6=C$. sinensis 'Valencia' (flavedo and albedo), lanes 7 and $8=C$. sinensis 'Washington Navel' (flavedo and albedo), lane 9=C. japonica (pericarp), lane 10=Olea europaea (Turkey) (leaf), lane 11=Olea europaea (Cyprus) (leaf), lane 12=Olea europaea (Turkey) (bark), lanes 13 and $14=C$. sinensis 'Shamouti' (flavedo), lane 15=C. sinensis 'Shamouti' (albedo). Volume of each sample was $10 \mu \mathrm{L}$, except in lane $13(5 \mu \mathrm{L})$ and lanes 14 and $15(15 \mu \mathrm{L})$

or no chelating capacity, which might be related to their phytochemical content.

\section{Conclusions}

The present study demonstrated that, among the seventeen cultivars of Citrus and the leaf and bark samples of Olea europaea, the maximum BChE inhibition was caused by the flavedo extract of C. limon 'Cyprus', followed closely by the seed extract of $C$. maxima. Our results indicated that the albedo and flavedo extracts showed diverse levels of BChE inhibition, which might mainly depend on the difference in their phytochemical content. The screened Citrus extracts had a selective BChE inhibitory and no AChE inhibitory activity at all. The extracts had either no or low metal-chelating capacity. To the best of our knowledge, this is the first study disclosing cholinesterase inhibitory and metal-chelating activities of the Citrus species cultivated in Turkey as well as of O. europaea growing in Turkey and Cyprus, and also the first HPTLC fingerprinting of these plants. Overall, the aforementioned Citrus extracts could be considered as BChE inhibitors rather than AChE inhibitors.

\section{Acknowledgements}

The authors gratefully extend their appreciation to CAMAG (Muttenz, Switzerland) R\&D laboratory for HPTLC fingerprinting of the plant samples.

\section{References}

1. Schneider LS, Mangialasche F, Andreasen N, Feldman $H$, Giacobini E, Jones R, et al. Clinical trials and late-stage drug development for Alzheimer's disease: an appraisal from 1984 to 2014. J Intern Med. 2014;275:251-83.

http://dx.doi.org/10.1111/joim.12191

2. Orhan G, Orhan I, Subutay-Oztekin N, Ak F, Sener B. Contemporary anticholinesterase pharmaceuticals of natural origin and their synthetic analogues for the treatment of $\mathrm{Al}$ zheimer's disease. Recent Pat CNS Drug Discov. 2009;4:43-51. http://dx.doi.org/10.2174/157488909787002582

3. Greig NH, Utsuki T, Yu QS, Zhu X, Holloway HW, Perry TA, et al. A new therapeutic target in Alzheimer's disease treatment: attention to butyrylcholinesterase. Curr Med Res Opin. 2001;17:159-65.

http://dx.doi.org/10.1185/03007990152673800

4. Lee S, Zheng X, Krishnamoorthy J, Savelieff MG, Park $\mathrm{HM}$, Brender JR, et al. Rational design of a structural framework with potential use to develop chemical reagents that target and modulate multiple facets of Alzheimer's disease. J Am Chem Soc. 2014;136:299-310. http://dx.doi.org/10.1021/ja409801p

5. Kawada H, Kador PF. Orally bioavailable metal chelators and radical scavengers: multifunctional antioxidants for the coadjutant treatment of neurodegenerative diseases. J Med Chem. 2015;58:8796-805. http://dx.doi.org/10.1021/acs.jmedchem.5b00272

6. Maqsood SR, Khan B, Bhat MA, Dar TA, Mir SH. Targeting copper induced oxidative damage to proteins by ligation: a novel approach towards chelation therapy for oxidative stress disorders. New J Chem. 2015;39:2720-7. http://dx.doi.org/10.1039/C4NJ02073A 
7. Nogata Y, Sakamoto K, Shiratsuchi H, Ishii T, Yano M, Ohta $\mathrm{H}$. Flavonoid composition of fruit tissues of Citrus species. Biosci Biotechnol Biochem. 2006;70:178-92. http://dx.doi.org/10.1271/bbb.70.178

8. Gorinstein S, Martín-Belloso O, Park YS, Haruenkit R, Lojek A, Ĉiz M, et al. Comparison of some biochemical characteristics of different Citrus fruits. Food Chem. 2001;74:309-15. http://dx.doi.org/10.1016/S0308-8146(01)00157-1

9. Ellman GL, Courtney KD, Andres Jr. V, Featherstone RM. A new and rapid colorimetric determination of acetylcholinesterase activity. Biochem Pharmacol. 1961;7:88-95. http://dx.doi.org/10.1016/0006-2952(61)90145-9

10. Orhan IE, Belhattab R, Senol FS, Gulpinar AR, Hosbas S, Kartal M. Profiling of cholinesterase inhibitory and antioxidant activities of Artemisia absinthium, A. herba-alba, A. fragrans, Marrubium vulgare, M. astranicum, Origanum vulgare subsp. glandulossum and essential oil analysis of two Artemisia species. Ind Crops Prod. 2010;32:566-71. http://dx.doi.org/10.1016/j.indcrop.2010.07.005

11. Chua MT, Tung YT, Chang ST. Antioxidant activities of ethanolic extracts from the twigs of Cinnamomum osmophleum. Bioresour Technol. 2008;99:1918-25. http://dx.doi.org/10.1016/j.biortech.2007.03.020

12. Kim DI, Lee SH, Hur EY, Cho SM, Park HJ. Screening of natural plant resources with acetylcholinesterase inhibition and antioxidant activity. J Korean Soc Food Sci Nutr. 2005;34:427-32. http://dx.doi.org/10.3746/jkfn.2005.34.3.427

13. Miyazawa M, Tougo H, Ishihara M. Inhibition of acetylcholinesterase activity by essential oil from Citrus paradisi. Nat Prod Lett. 2001;15:205-10. http://dx.doi.org/10.1080/10575630108041281

14. Heo HJ, Kim DO, Shin SC, Kim MJ, Kim BG, Shin DH. Effect of antioxidant flavanone, naringenin, from Citrus junos on neuroprotection. J Agric Food Chem. 2004;52:1520-5. http://dx.doi.org/10.1021/jf035079g

15. Conforti F, Statti GA, Tundis R, Loizzo MR, Menichini F. In vitro activities of Citrus medica L. cv. Diamante (Diamante citron) relevant to treatment of diabetes and Alzheimer's disease. Phytother Res. 2007;21:427-33. http://dx.doi.org/10.1002/ptr.2077

16. Youkwan J, Sutthivaiyakit $S$, Sutthivaiyakit P. Citrusosides A-D and furanocoumarins with cholinesterase inhibitory activity from the fruit peels of Citrus hystrix. J Nat Prod. 2010; 73:1879-83. http://dx.doi.org/10.1021/np100531x

17. Kimura J, Nemoto $K$, Onoue S, Yamakuni T, Yokosuka A, Mimaki Y, et al. Inhibitory effects of Citrus polymethoxyflavones, nobiletin and its analogues, on acetylcholinesterase activity. Pharmacometrics. 2011;81:23-6.

18. Tundis R, Loizzo MR, Bonesi M, Menichini F, Mastellone V, Colica C, Menichini F. Comparative study on the antioxidant capacity and cholinesterase inhibitory activity of Citrus aurantifolia Swingle, C. aurantium L., and C. bergamia Risso and Poit. peel essential oils. J Food Sci. 2012;77:H40-6. http://dx.doi.org/10.1111/j.1750-3841.2011.02511.x

19. Chaiyana W, Okonogi S. Inhibition of cholinesterase by essential oil from food plant. Phytomedicine 2012;19:836-9. http://dx.doi.org/10.1016/j.phymed.2012.03.010

20. Loizzo MR, Tundis R, Bonesi M, Menichini F, De Luca D, Colica $\mathrm{C}$, et al. Evaluation of Citrus aurantifolia peel and leaves extracts for their chemical composition, antioxidant and anti-cholinesterase activities. J Sci Food Agric. 2012;92:2960-7. http://dx.doi.org/10.1002/jsfa.5708

21. Ademosun AO, Oboh G. Inhibition of acetylcholinesterase activity and $\mathrm{Fe}^{2+}$-induced lipid peroxidation in rat brain in vitro by some citrus fruit juices. J Med Food. 2012;15:428-34. http://dx.doi.org/10.1089/jmf.2011.0226

22. Ademosun AO, Oboh G. Anticholinesterase and antioxidative properties of water-extractable phytochemicals from some Citrus peels. J Basic Clin Physiol Pharmacol. 2014;25: 199-204. http://dx.doi.org/10.1515/jbcpp-2013-0027

23. Gironés-Vilaplana A, Valentão $P$, Andrade PB, Ferreres $F$, Moreno DA, García-Viguera C. Beverages of lemon juice and exotic noni and papaya with potential for anticholinergic effects. Food Chem. 2015;170:16-21. http://dx.doi.org/10.1016/j.foodchem.2014.08.021

24. Remya C, Dileep KV, Tintu I, Variyar EJ, Sadasivan C. Flavanone glycosides as acetylcholinesterase inhibitors: computational and experimental evidence. Indian J Pharm Sci. 2014; 76:567-70.

25. Sun Y, Qiao L, Shen Y, Jiang P, Chen J, Ye X. Phytochemical profile and antioxidant activity of physiological drop of Citrus fruits. J Food Sci. 2013;78:C37-42. http://dx.doi.org/10.1111/j.1750-3841.2012.03002.x

26. Zhang Y, Sun Y, Xi W, Shen Y, Qiao L, Zhong L, et al. Phenolic compositions and antioxidant capacities of Chinese wild mandarin (Citrus reticulata Blanco) fruits. Food Chem. 2014;145:674-80. http://dx.doi.org/10.1016/j.foodchem.2013.08.012

27. Ouattara N, Meda RNT, Hilou A, Guenné S, Konaté K, Coulibaly AY, et al. Anti-acetylcholinesterase and antioxidant activities and HPLC-MS analysis of polyphenol from extracts of Nelsonia canescens (Lam.) Spreng. Asian Pac J Trop Dis. 2013;3:382-8. http://dx.doi.org/10.1016/S2222-1808(13)60088-2

28. Chan HH, Hwang TL, Su CR, Reddy MVB, Wu TS. Anti-inflammatory, anticholinesterase and antioxidative constituents from the roots and the leaves of Salvia nipponica Miq. var. formosana. Phytomedicine. 2011;18:148-50. http://dx.doi.org/10.1016/j.phymed.2010.06.017

29. Orhan I, Kartal M, Tosun F, Şener B. Screening of various phenolic acids and flavonoid derivatives for their anticholinesterase potential. Z Naturforsch C. 2007;62:829-32. http://dx.doi.org/10.1515/znc-2007-11-1210

30. Amoo SO, Aremu AO, Moyo M, Van Staden J. Antioxidant and acetylcholinesterase-inhibitory properties of long-term stored medicinal plants. BMC Complement Altern Med. 2012; 12:Article no. 87. http://dx.doi.org/10.1186/1472-6882-12-87

31. Ramful D, Bahorun T, Bourdon E, Tarnus E, Aruoma OI. Bioactive phenolics and antioxidant propensity of flavedo extracts of Mauritian citrus fruits: potential prophylactic ingredients for functional foods application. Toxicology. 2010;278: 75-87. http://dx.doi.org/10.1016/j.tox.2010.01.012

32. Kim MY. Free radical scavenging and ferrous ion chelating activities of Citrus fruits derived from induced mutations with gamma irradiation. Life Sci J. 2013;10:401-3. 